\title{
Molecular mechanisms of acclimation to long- term elevated temperature exposure in marine symbioses
}

Alves Monteiro H.J. ${ }^{1}$, Brahmi C. ${ }^{2}$, Mayfield A.B. ${ }^{3,4}$, Vidal-dupiol J. ${ }^{5}$, Lapeyre B. ${ }^{6}$, Le Luyer Jeremy ${ }^{1,}$,

1 IFREMER EIO UMR 241 Labex CORAIL Unité RMPF Centre Océanologique du Pacifique Vairao

Tahiti, Polynésie française

2 Université de la Polynésie Française EIO UMR 241 Labex CORAIL Tahiti , Polynésie française

${ }^{3}$ National Museum of Marine Biology and Aquarium 2 Houwan Rd.Checheng Pingtung 944, Taiwan

${ }^{4}$ Atlantic Oceanographic and Meteorological Laboratory National Oceanic and Atmospheric

Administration Miami FL 33149, USA

5 IHPE Univ. Montpellier CNRS Ifremer Univ. Perpignan Via Domitia Montpellier, France

${ }^{6}$ EPHE-UPVD-CNRS CRIOBE USR 3278 Labex CORAIL Université de Perpignan Perpignan, France

* Corresponding author : Jeremy Le Luyer, email address : Jeremy.le.luyer@ifremer.fr

\begin{abstract}
:
Seawater temperature rise in French Polynesia has repeatedly resulted in the bleaching of corals and giant clams. Because giant clams possess distinctive ectosymbiotic features, they represent a unique and powerful model for comparing molecular pathways involved in 1) maintenance of symbiosis and 2) acquisition of thermo-tolerance among coral reef organisms. Herein, we explored the physiological and transcriptomic responses of the clam hosts and their photosynthetically active symbionts over a 65-day experiment in which clams were exposed to either normal or environmentally relevant elevated seawater temperatures. Additionally, we used metabarcoding data coupled with in situ sampling/survey data to explore the relative importance of holobiont adaptation (i.e., a symbiont community shift) versus acclimation (i.e., physiological changes at the molecular level) in the clams' responses to environmental change. We finally compared transcriptomic data to publicly available genomic datasets for Symbiodiniaceae dinoflagellates (both cultured and in hospite with the coral Pocillopora damicornis) to better tease apart the responses of both hosts and specific symbiont genotypes in this mutualistic association. Gene module preservation analysis revealed that the function of the symbionts' photosystem II was impaired at high temperature, and this response was also found across all holobionts and Symbiodiniaceae lineages examined. Similarly, epigenetic modulation appeared to be a key response mechanism for symbionts in hospite with giant clams exposed to high temperatures, and such modulation was able to distinguish thermo-tolerant from thermo-sensitive Cladocopium goreaui ecotypes; epigenetic processes may, then, represent a promising research avenue for those interested in coral reef conservation in this era of changing global climate.
\end{abstract}

Keywords : co-expression network analysis, giant clams, metabarcoding, RNA-Seq, Symbiodiniaceae, thermo-acclimation 


\section{Introduction}

The "small giant" clams (Tridacna maxima; hereafter referred to as simply "clams") are mixotrophic organisms living in obligatory symbiosis with photosynthetic dinoflagellates of the family Symbiodiniaceae (Holt, Vahidinia, Gagnon, Morse, \& Sweeney, 2014; Jantzen et al., 2008; LaJeunesse et al., 2018). Symbiodiniaceae associate not only with clams, but with a diverse array of marine invertebrates, namely sponges, molluscs, and cnidarians; indeed, the coral-Symbiodiniaceae symbiosis is the functional basis of all coral reefs (Hughes et al., 2003). Whereas in scleractinian corals symbionts are located intracellularly, in clams they reside extracellularly inside a tubular system ("Z-tubules"), which is 1) found in the outer epithelium of the mantle and 2) connected to the stomach (Norton, Shepherd, Long, \& Fitt, 1992). These in hospite dinoflagellates are known to provide nutrients to their clam hosts via photosynthesis and may account for a major part of the clams' energy needs (depending on the species and the life history stage) (Hawkins \& Klumpp, 1995; Klumpp, Bayne, \& Hawkins, 1992; Klumpp \& Griffiths, 1994; Lucas, 1994; Soo \& Todd, 2014).

The systematics of the family Symbiodiniaceae have recently been revised to include at least nine different genera (formerly referred to as "clades") with well characterized molecular and physiological differences (LaJeunesse et al., 2018). One Symbiodiniaceae genus, formerly known as clade A (which includes the species Symbiodinium fitti, S. microadriaticum, and S. tridacnidorum), has been recurrently found in symbiosis with T. maxima, though members of clades C (Cladocopium) and D (Durusdinium) have been found in clam tissues, as well (Baillie, Belda-Baillie, \& Maruyama, 2000; DeBoer et al., 2012; Ikeda et al., 2017; LaJeunesse, 2001; Lee et al., 2015; Mies, Van Sluys, Metcalfe, \& Sumida, 2017; Pinzón, Devlin-Durante, Weber, Baums, \& LaJeunesse, 2011). Depending on the clam species, the symbiont assemblage has been found to vary with individual size (mostly observed in T. squamosa), as well as across environmental gradients (especially seawater temperatures) (DeBoer et al., 2012; Ikeda et al., 2017).

In French Polynesia, eastern Tuamotu's archipelagos were historically characterized by high densities of clams (Andréfouët et al., 2013; Gilbert et al., 2005; Gilbert, Remoissenet, Yan, \& Andrefouet, 2006). Recent mortality episodes and/or "bleaching" events in the Tuamotu Islands have, 
however, been reported, including 1) a massive mortality event in 2009 that reduced the clam population by $90 \%$ at Tatakoto Atoll (Andréfouët et al., 2013; Van Wynsberge, Andréfouët, GaertnerMazouni, \& Remoissenet, 2018) and 2) a bleaching event in 2016 that affected 77 and $90 \%$ of the wild and cultured giant clam populations, respectively, at Reao Atoll (Andréfouët et al., 2017). An increase in surface seawater temperature over a prolonged period (approximately three months above $30^{\circ} \mathrm{C}$ ) is suspected to have triggered such bleaching events (Andréfouët et al., 2013, 2017; Van Wynsberge et al., 2018).

As with corals, bleaching in clams corresponds to the loss of symbiotic Symbiodiniaceae from the hosts (Andréfouët et al., 2013; Buck, 2002; Fitt, Brown, Warner, \& Dunne, 2001; HoeghGuldberg et al., 2007; Leggat, Buck, Grice, \& Yellowlees, 2003). Symbiodiniaceae community variability and diversity (i.e., the collective assemblage of various genera and/or species) seems to be a determining factor in the sensitivity and resilience of both coral and clam hosts to increased temperatures (Barshis, Ladner, Oliver, \& Palumbi, 2014; Barshis et al., 2013; Ladner, Barshis, \& Palumbi, 2012; Rowan, Knowlton, Baker, \& Jara, 1997). However, the cell physiology of the host and symbionts is likely to be as important, if not more so, than the Symbiodiniaceae assemblage, in terms of gauging the ability of the clam-Symbiodiniaceae symbiosis to acclimate to elevated temperature over prolonged durations.

To date, few studies have investigated the transcriptomic response of giant clams to elevated temperatures; lipid profiling analyses are more routinely undertaken (Dubousquet et al., 2016). The transcriptomic response to elevated temperature of several other taxa, mostly scleractinian coral species (Crowder, Meyer, Fan, \& Weis, 2017; Hou et al., 2018; Kenkel \& Matz, 2016; Pinzón et al., 2015) and cultured Symbiodiniaceae (Gierz, Forêt, \& Leggat, 2017; Levin et al., 2016) have also been explored, yet few studies have looked at the mRNA level responses of multiple Symbiodiniaceae clades and host systems in the same study. Furthermore, few physiological data and even fewer transcriptomic data are available for the high-temperature responses of the giant clam T. maxima and its symbionts [but see (Dubousquet et al., 2016; Zhou, Liu, Wang, Luo, \& Li, 2018)]; these two published studies, though, only considered the response to an abrupt, rapid increase in temperature (short-term stress response).

This article is protected by copyright. All rights reserved 
Consequently, our understanding of the possible key drivers in high-temperature acclimation remains largely incomplete, despite its importance in generating better predictions of the impact of climate change on wild populations of giant clams (Van Wynsberge et al., 2018). Given such knowledge deficiencies, we aimed herein to characterize the physiological and transcriptomic responses of clams and their symbionts to hypothetically sub-lethal elevated temperatures $\left(\sim 30.7^{\circ} \mathrm{C}\right.$ over a two-month period) that aimed to mimic past episodes of anomalously high temperatures in French Polynesia. In addition to hypothesizing that the giant clams would ultimately acclimate to this experimentally elevated temperature, we further hypothesized that a "dual-compartmental" bioinformatic approach, similar to the one that has been used with corals (Mayfield, Wang, Chen, Lin, \& Chen, 2014), would provide insight into the key molecular pathways underlying the ability of each member of this association to acclimate to an environmentally relevant, sub-lethal temperature.

\section{Materials and Methods}

\section{Experimental design, tissue sampling, and physiological measurements}

The experimental procedures were first described by Brahmi et al. (2019). Briefly, 24 individual clams ( $\mathrm{N}=4 /$ treatment) were sampled over a 65 -day period (days 29,53 , and 65$)$ in control $\left(29.2^{\circ} \mathrm{C}\right.$; ambient at the time of experimentation) and elevated $\left(30.7^{\circ} \mathrm{C}\right)$ temperature conditions. The temperatures employed and the duration of the experiment reflect conditions in normal and abnormally hot seasons, respectively [(correlated with mass clam bleaching events (Addessi, 2001)] reported in lagoons of French Polynesia's Tuamotu region (Brahmi et al., 2019).

Samples (approx. $1 \mathrm{~cm}^{2}$ ) from each of the two treatments at each of the three sampling times were systematically collected from the same region of the mantle and stored in RNALater ${ }^{\circledR}$ (Life Technologies, USA) at $-80^{\circ} \mathrm{C}$ until analysis $(\mathrm{N}=24)$. Furthermore, a single hermaphroditic individual (approximately two years old) was sampled for a total of seven different tissues (mantle, adductor muscle, gonads, gills, byssus, visceral mass, and kidney) for transcriptome assembly. Only one individual was used in an effort to reduce assembly polymorphism biases. For this individual, which was excluded from the quantification analysis outlined below, sexual status was confirmed by gonad biopsy and histology following a previously detailed procedure (Menoud et al., 2016). Additionally, 10 giant clams were collected in situ in October 2018 around Reao Atoll (Tuamotu Archipelago,

This article is protected by copyright. All rights reserved 
French Polynesia); tissues from each of these in situ individuals were collected from the same region of the mantle (approx. $1 \mathrm{~cm}^{2}$ ) and stored in $95 \%$ ethanol at $-20^{\circ} \mathrm{C}$ until later symbiont community analysis (described below).

As described in detail in Brahmi et al. (2019), a variety of physiological response variables were assessed in the 24 experimental replicates, in addition to the profiling of their transcriptomes: growth, Symbiodiniaceae density, and the maximum dark-adapted yield of photosystem II (Fv/Fm; as measured by an AquaPen pulse amplitude modulating fluorometer; APC-100m, Photon System Instruments, Czech Republic). Please see Brahmi et al. (2019) for details on these analyses. Physiological data were tested with two-way ANOVA (treatment x time) followed by Tukey's "honestly significant difference" (HSD) post-hoc tests $(p<0.05)$, including the interaction between time and temperature, when data (raw or transformed) met the assumptions for ANOVA. For Symbiodiniaceae density and Fv/Fm, a non-parametric equivalent of the two-way ANOVA, the Scheirer-Ray-Hare test, was instead used (followed by Dunn's post-hoc tests).

\section{DNA/RNA extractions and transcriptome sequencing}

Total RNA was extracted from T. maxima mantles by lacerating tissues with a scalpel and rinsing with 1X PBS. Cellular lysis was induced by addition of $1.5 \mathrm{ml}$ TRIzol (Invitrogen, USA) according to the manufacturer's recommendations. The supernatant was transferred into a 2-ml tube and incubated for $10 \mathrm{~min}$ on ice. Phase separation was achieved by addition of $300 \mu \mathrm{l}$ of chloroform coupled with centrifugation at $12,000 \mathrm{xg}$ for $12 \mathrm{~min}$ at $4^{\circ} \mathrm{C}$. The upper aqueous layer contained the RNA, and the lower organic layer was stored at $-20^{\circ} \mathrm{C}$ for later DNA extraction (according to the manufacturer's recommendations). Total RNA from each individual was subjected to a DNAse treatment using Qiagen's RNA cleanup kit (Germany). RNA and DNA were quantified using a NanoDrop ND-2000 spectrophotometer (Thermo-Fisher, USA), and RNA quality was further evaluated by a Bioanalyzer 2100 (Agilent, USA). High-quality RNA was sent to McGill University's "Genome Quebec

Innovation Center” (Montréal, QC, Canada) for Nextera XT (Illumina; USA) library preparation and sequencing on an Illumina HiSeq4000 100-bp paired-end platform. Samples for transcriptome assembly $(\mathrm{N}=7)$ were sequenced on a single lane, while samples for expression level quantification analysis $(\mathrm{N}=24)$ were uniformly and randomly distributed over two sequencing lanes after barcoding.

This article is protected by copyright. All rights reserved 


\section{Transcriptomes assembly}

Raw reads provided by RNA-Seq were filtered for quality and length using Trimmomatic v.0.36 (Bolger, Lohse, \& Usadel, 2014) with minimum length, trailing, and leading quality parameters set to $60 \mathrm{bp}, 20$, and 20, respectively. Illumina's adaptors and residual cloning vectors were removed via the UNIVEC database (https://www.ncbi.nlm.nih.gov/tools/vecscreen/univec/). Paired-end filtered reads were assembled de novo using Trinity v2.6.6 (Haas et al., 2013) with a default k-mer size of $25 \mathrm{bp}$ and a minimum transcript length of $200 \mathrm{bp}$. Raw transcripts ( $\mathrm{n}=726,689 ; 420 \mathrm{Gbp}$ ) were filtered for presence of open reading frames (ORFs) (length $\geq 300 \mathrm{bp}$ ), longest isoform matches, and mapping rate $(\geq 0.5$ transcripts per million; TPM).

Transcripts matching Refseq entries from archaea, plasmids, viruses, and bacteria (BLASTn; $e$ value $<10^{-10}$ ), as well those transcripts that aligned significantly (e-value $\left.<10^{-4}\right)$ only to bacterial sequences in the NCBI nt database (max target seqs $=5$ ) were discarded in an effort to reduce putative contamination. To segregate between symbiont and host sources, the meta-transcriptome was blasted (BLASTn; $e$-value $<10^{-4}$ ) against a pool of Symbiodiniaceae genomes and transcriptomes including former clades A, C, and F [sensu (González-Pech, Ragan, \& Chan, 2017)]. By default, all hits with no match were considered as originating from the host. For quality control, the de novo transcriptome's completeness was assessed with BUSCO's v2 metazoa and v2 eukaryotes databases for clam and Symbiodiniaceae, respectively (Simão, Waterhouse, Ioannidis, Kriventseva, \& Zdobnov, 2015). Transcriptomes were annotated by BLAST search against the Uniprot-Swissprot database (BLASTx; $e$-value $<10^{-4}$ ). A schematic representation of the overall analysis pipeline has been provided in the Github repository (https://github.com/jleluyer/acclimabest).

\section{Compartment-specific responses of the clam-dinoflagellate holobiont to long-term temperature exposure}

Filtered reads were mapped against a combined host-symbiont transcriptome using GSNAP v2018.07.04 (Wu, Reeder, Lawrence, Becker, \& Brauer, 2016) using the default parameters but allowing for a maximum mismatch value of 3 and a minimum coverage of 0.85 . Only properly paired and uniquely mapped reads were conserved for downstream analysis ("concordant_uniq;" Wu,

Reeder, Lawrence, Becker, \& Brauer, 2016). Gene counts were conducted with HTSEQ v0.11.2 (Anders, Pyl, \& Huber, 2015) using the default parameters. A filtering step including removal of 
genes with residual expression $>1$ count per million (CPM) in 4 individuals was applied, and data were transformed using the "rlog" function (betaPriorVar=2) implemented in the DESeq2 v1.23.10 R package (Love, Huber, \& Anders, 2014) for host and symbionts separately.

Signed co-expression networks were built for the host and symbiont datasets independently using the R package WGCNA with a filtering step for minimum overall variance $(>10 \%)$ following the recommendations of Langfelder \& Horvath (2008). The main goal of this analysis was to cluster genes in modules correlated with time, temperature, and relevant physiological responses (Figure 1). Briefly, we fixed "soft" threshold powers of 6 and 11 for the host and symbiont datasets, respectively, using the scale-free topology criterion to reach a model fit $(|\mathrm{R}|)$ of 0.90 and 0.80 , respectively. The modules were defined using the "cutreeDynamic" function (minimum of 50 genes by module and default cutting-height $=0.99$ ) based on the topological overlap matrix, and an automatic merging step with the threshold fixed at 0.25 (default) allowed us to merge correlated modules. For each module, we defined the module membership (kME; Eigengene-based connectivity), and only statistically significant $(p<0.05)$ modules were conserved for downstream functional analysis (Figure 1). Gene ontology (GO) enrichment analyses were conducted for each module using the GO_MWU R package (Wright, Aglyamova, Meyer, \& Matz, 2015) based on the background gene dataset found in WGCNA. GO terms were considered enriched at Benjamini-Hochberg adj. $p<0.05$ (minimum of three genes for any individual GO term).

\section{Meta-analysis of cultured and in hospite Symbiodiniaceae transcriptomes}

We integrated publicly available datasets featuring similar experimental designs (i.e. control and elevated temperature conditions over a long-term timescale) to further unravel conserved symbiont responses across genera, holobionts, and culture environments (i.e., cultured vs. in hospite). Manuscript searches were conducted with the Web of Science platform using the search formula: «symbio* AND RNAseq* AND temperature» together with informal searches via other research engines (e.g., Google Scholar). A total of three studies met our criteria: Levin et al. (2016) and Gierz et al. (2017) for cultured Symbiodiniaceae ( $n=48$ transcriptomes) and Mayfield et al. (2014) for the response of Symbiodiniaceae in hospite with the scleractinian coral P. damicornis ( $\mathrm{n}=12$ transcriptomes). Gierz et al. (2017) exposed cultured Symbiodiniaceae (Fugacium kawagutii; formerly clade $\mathrm{F}$ ) to a $31^{\circ} \mathrm{C}$ heat stress (control temperature $=24.5^{\circ} \mathrm{C}$ ) over a 28 -day period, while 
Levin et al. (2016) exposed Symbiodiniaceae (Cladocopium goreaui; formerly type C1; including established thermo-tolerant and thermo-sensitive phenotypes) to a $32^{\circ} \mathrm{C}$ heat stress (control temperature $=27^{\circ} \mathrm{C}$ ) over a 13-day period. Finally, Mayfield et al. (2014) exposed corals housing Symbiodiniaceae (Cladocopium spp.; formerly a mixed assemblage of clade $\mathrm{C}$ individuals) to $30^{\circ} \mathrm{C}$ over a 9-month period (control temperature $=27^{\circ} \mathrm{C}$ ), and both the coral hosts and in hospite Symbiodiniaceae appeared to have acclimated to this temperature.

Raw data processing followed the same procedure as described above, though adapted for single-end reads for cultured Symbiodiniaceae datasets. To explore the convergence of Symbiodiniaceae responses despite large phylogenetic differences across the Symbiodiniaceae genera (Symbiodinium, Cladocopium, and Fugacium; LaJeunesse et al., 2018), we first searched for singlecopy orthologs across the three genera using OrthoFinder v2.2.7 (Emms \& Kelly, 2015) based on publicly available genomes (http://reefgenomics.org/; Liu et al., 2018). We found a total of 4,215 ortho-groups that were used for downstream analyses. The count matrix was filtered for low residual expression genes (>1 CPM in 40 individuals; 4,187 remaining genes), and raw count data were transformed using the "vst" function implemented in the DESeq2 R package (Love et al., 2014). We used the "removeBatchEffect" function implemented in the Limma R package (Ritchie et al., 2015) to remove experimental effects and fit the data prior the downstream analyses.

We then used a combination of redundant discriminant analysis (RDA) and partial dbRDAs approaches to assess the effect of temperature across Symbiodiniaceae clades and experiments. First, we computed a Euclidian distance matrix and performed a principal coordinates analysis (PCoA) on this Euclidian distance matrix using the "daisy" and "pcoa" functions, respectively, implemented in the "ape" R package (Paradis, Claude, \& Strimmer, 2004). Only PCo axes explaining at least $2.5 \%$ of the total variance were kept for downstream analysis (Legendre \& Gallagher, 2001; Legendre \& legendre, 2012). To test for the effect of temperature and time, a distance-based redundancy analysis (db-RDA) was also produced with the retained PCo factors $(n=8)$ as a response matrix and the yariables temperature, experiment, and time as the explanatory factors. We first carried out stepwise model selection to identify relevant explanatory variables using the "ordistep" function implemented in the vegan R package (Oksanen et al., 2012) and ultimately retained only temperature and time $(p<0.05)$. Partial db-RDAs were therefore produced to test for the effects of these two parameters

This article is protected by copyright. All rights reserved 
alone (no effect of experiment or genotype) after constraining the remaining variables. The effect of a given factor was considered significant when $p<0.05$. Finally, we used a weighted co-expression network analysis with WGCNA (similar thresholds as described above but with soft power fixed at 14) to reach a model fit $(|\mathrm{R}|)$ of 0.83 , and subsequent module-wise GO enrichment analyses were undertaken using the GO_MWU R package (Wright et al., 2015).

\section{Genomic basis of thermotolerance in Symbiodiniaceae dinoflagellates}

We used an independent WGCNA co-expression network analysis to search for specific gene modules correlated with thermotolerance. For this purpose we focused on the dataset of Levin et al. (2016), with Cladocopium goreaui as the reference genome (Liu et al., 2018). Indeed, this is the only study to our knowledge featuring established thermotolerant phenotypes with transcriptomic data on long-term time series. The WGCNA analysis followed similar steps as described previously based, though based on rlog-transformed data (betaPrior=2). The soft threshold power was fixed at 20 to reach a model fit $(|\mathrm{R}|)$ of 0.85 . The downstream, module-wise GO enrichment analyses followed the pipeline outlined above. Finally, we used the 'GO_deltaRanks_correlation' function implemented in the GO_MWU R package (Wright et al., 2015) to assess similarity between response to stress in symbiont in hospite with clams in and specific mechanisms of thermotolerance for cultured Symbiodiniaceae.

\section{Quantitative PCR- and meta-barcoding-based Symbiodiniaceae analysis}

We evaluated the relative levels of various Symbiodiniaceae genera in our clam samples using a series of quantitative PCR (qPCR) assays. Amplifications were carried out on AriaMx real-time PCR System (Agilent, USA) using six primer sets optimized for the amplification of nuclear ribosomal $28 \mathrm{~S}$ in Symbiodiniaceae of clades/genera A-F (Yamashita, Suzuki, Hayashibara, \& Koike, 2011) following the protocol of Rouzé et al. (2017). The PCRs $(25 \mu \mathrm{L})$ comprised $12.5 \mu \mathrm{L}$ of $2 \mathrm{X}$ SYBR ${ }$ Green master mix (Agilent, USA), $10 \mu \mathrm{L}$ of DNA (previously diluted to $1 \mathrm{ng} \mu \mathrm{L}^{-1}$ ), and $1.25 \mu \mathrm{L}$ of each primer (forward and reverse; each at a stock concentration of $4 \mu \mathrm{M}$ ). PCR thermocycling included: 1 cycle of pre-incubation for $10 \mathrm{~min}$ at $95^{\circ} \mathrm{C} ; 40$ cycles of amplification $\left(30 \mathrm{~s}\right.$ at $95^{\circ} \mathrm{C}, 1$ min at $64^{\circ} \mathrm{C}$, and $1 \mathrm{~min}$ at $\left.72^{\circ} \mathrm{C}\right)$, and a melting curve analysis that extended from $60^{\circ} \mathrm{C}$ to $95^{\circ} \mathrm{C}(30$-s

This article is protected by copyright. All rights reserved 
incubations). All measurements were made in duplicate, and all analyses were based on the threshold cycle $(\mathrm{Ct})$ values of the PCR products.

$\mathrm{Ct}$ values were averaged across duplicate samples when the variation was not exceeding 1; otherwise, samples were re-run until delta $\mathrm{Ct}<1$. Similarity in relative clade abundance was assessed using PCA analysis of a Bray-Curtis similarity matrix with Hellinger-transformed data. Db-RDAs were conducted to identify whether either temperature or time had a significant impact on Symbiodiniaceae assemblage, and an alpha level of 0.05 was set a priori. To complement data from the experimental individuals, qPCRs were carried out with DNA isolated from mantle fragments from the 10 wild individuals described above collected from Reao Atoll [geographically proximal to the origin of the experimental individuals; see Brahmi et al., (2019) for details.] in October 2018. Sample preparation and analyses were performed as described above and in Rouzé et al. (2017).

As a more detailed means of assessing Symbiodiniaceae diversity in the 24 clam samples, a meta-barcoding analysis was undertaken following the protocol of Cunning, Gates, \& Edmunds (2017). Briefly, the ITS2 gene was PCR amplified using previously described primers (Cunning, Gates, and Edmunds, 2017) and sequenced at the facility listed above, albeit on a Illumina Miseq 250bp paired-end platform. The Dada2 algorithm (Callahan et al., 2016) implemented in the QIIME2 software package (Bokulich et al., 2018) was used to infer exact sample sequences from amplicon data. The reference database was directly imported from the NCBI nt repository and trained on the basis of the ITS2 primers following Cunning, Gates, and Edmunds (2017). Detailed protocols and the corresponding scripts have been made available in a public Github repository (https://github.com/jleluyer/acclimabest).

\section{Results}

\section{Physiology}

We observed no mortality across the 65-day experiment, but some of the individuals exposed to elevated temperature showed signs of partial bleaching in the $30.7^{\circ} \mathrm{C}$ treatment by day 65 . Symbiodiniaceae density and photosynthetic yield $(\mathrm{Fv} / \mathrm{Fm})$ were both lower in clams exposed to elevated temperatures (Scheirer-Ray-Hare; $\mathrm{H}=24.44, p<0.001$ and $\mathrm{H}=22.88, p<0.001$, respectively; Figure S1). There was no interaction between time and temperature for Symbiodiniaceae Fv/Fm 
(Scheirer-Ray-Hare; $\mathrm{H}=1.26 ; p=0.53$, Figure $\mathrm{S} 1$ ). Time had only a slight effect on Symbiodiniaceae density (Scheirer-Ray-Hare; $\mathrm{H}=6.07 ; p=0.048$, Figure $\mathrm{S} 1$ ), though no post-hoc differences were detected between individual sampling times (Dunn's test; $p>0.05$ ).

\section{Symbiodiniaceae communities in hospite with clams}

The Symbiodiniaceae communities of all clam hosts (from both control and high temperature conditions) were primarily composed of Symbiodinium spp. (formerly clade A; Figure 1A). Four clams, however, were characterized by secondary populations of Cladocopium spp. (formerly clade $\mathrm{C}$; with relative proportions reaching 1.8 to $32.8 \%)$, as well as residual quantities $(<0.001 \%)$ of Breviolum (formerly clade B) and Fugacium (formerly clade F). There were no detectable effects of prolonged high-temperature exposure of the Symbiodiniaceae assemblages within the giant clam samples (Figure 1B). Similarly, in situ clam samples from Reao Atoll were also dominated by Symbiodinium spp. (mean $93.0 \% \pm 10.7 \mathrm{SD}$ ), with smaller populations of Breviolum spp. and Cladocopium spp. Given the similarities in Symbiodiniaceae assemblages between the experimental and in situ specimens, we conclude that transport out of the ocean and into the aquarium husbandry facility did not result in community changes that could bias the results described below.

Metabarcoding of the internal transcribed spacer 2 (ITS2) sequence resulted in an average of 186.7k \pm 25.7 PE sequences per sample. After sequence pre-processing, the Dada2 algorithm reported a total of 12 amplicon sequence variants matching to Symbiodinium spp. (N=9) and Cladocopium spp. $(\mathrm{N}=3)$ that paralleled results from qPCRs. Symbiodinium sequence variants mainly matched to $S$. tridacnidorum (formerly sub-clade A3; best-hit BLASTn e-value $<10^{-6}$ ). Neither cladal/genera representation based on UniFrac distance (PERMANOVA; pseudo- $F=1.3 ; q$-value $=0.33$ ) nor evenness values (Kruskall-Wallis; $\mathrm{H}=0.04 ; \quad q$-value $=0.83$ ) differed significantly between temperatures.

This article is protected by copyright. All rights reserved 
A

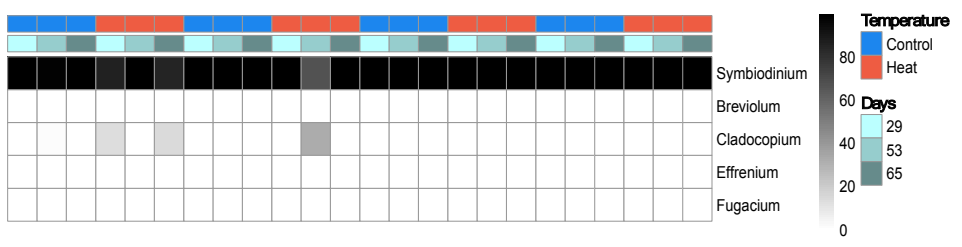

B

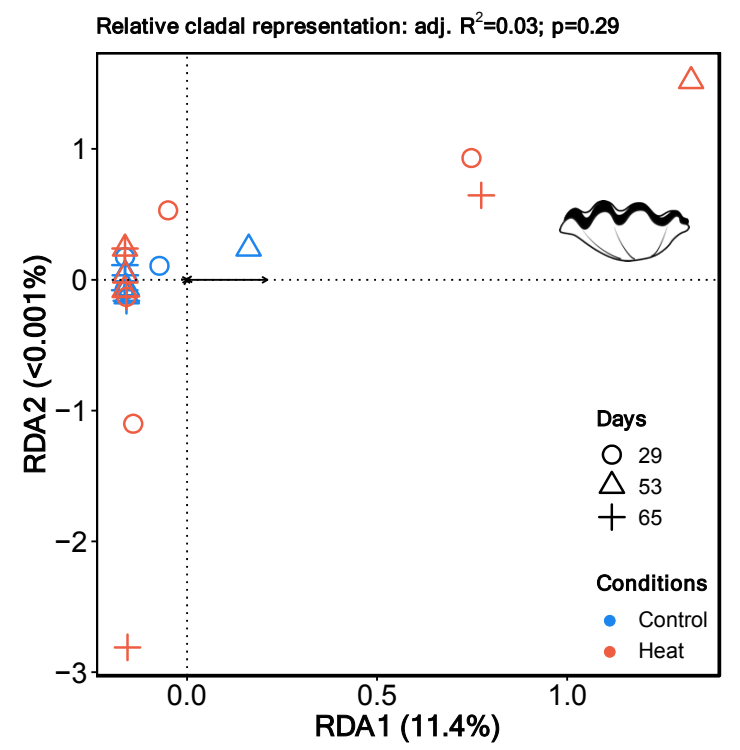

Figure 1: Symbiodiniaceae community representation assessed by $\mathrm{qPCR}$, metabarcoding, and multivariate analysis. (A) Heatmap showing the median relative clade proportion by group $(\mathrm{N}=4$ individuals/group), as determined by qPCR. (B) RDA representation based on PCoA of Euclidian distances.

\section{Transcriptome assemblies}

A total of 363.70 million 100-bp paired-end reads were used to assemble a raw metatranscriptome (host + symbionts) of 726,689 transcripts (420.02 Gbp). After stringent filtering and segregation of host and Symbiodiniaceae sequences, the assemblies resulted in a transcriptome for $T$. maxima of 24,234 contigs ( $\mathrm{N} 50=1,011 \mathrm{bp}$; $\mathrm{GC}$ content $=40.1 \%$ ) and a meta-transcriptome for Symbiodiniaceae of 51,648 contigs $(\mathrm{N} 50=1,027 \mathrm{bp}$; GC content $=57.9 \%)$. High G-C content is 
generally a hallmark of Symbiodiniaceae transcriptomes (González-Pech et al., 2017). Transcriptome statistics and annotations are provided in Figure 2 and Table S1, respectively.

A

\begin{tabular}{ll}
\hline Tridacna maxima & \\
\hline \hline Total number of transcripts & 24,234 \\
Average percent G-C & 40.15 \\
Contig N50 & 1,768 \\
Median contig length (bp) & 1,011 \\
Average contig length (bp) & $1,276.13$ \\
Total assembled bases & $30,925,845$ \\
& \\
Symbiodinium spp. & \\
\hline \hline Total number of transcripts & 51,648 \\
Average percent G-C & 57.9 \\
Contig N50 & 1,027 \\
Median contig length (bp) & 688 \\
Average contig length (bp) & 845.89 \\
Total assembled bases & $43,688,343$ \\
\hline
\end{tabular}

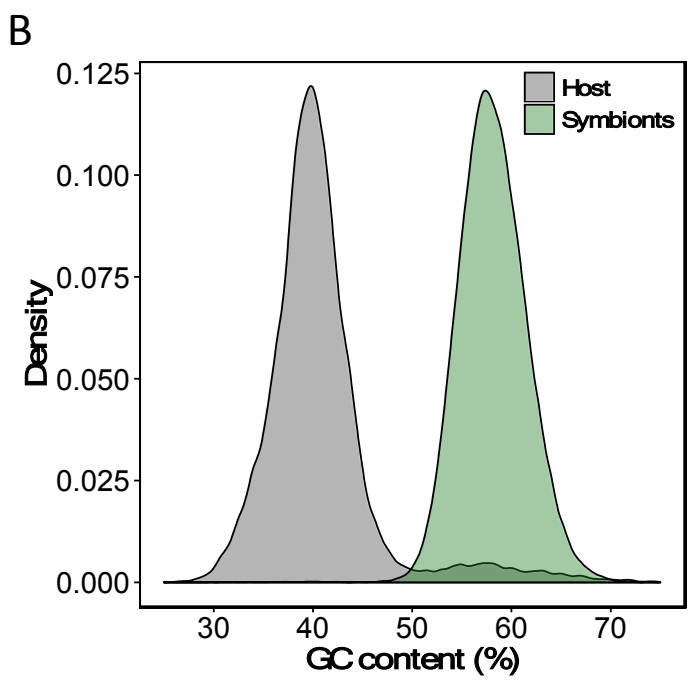

Figure 2: Transcriptome assembly statistics. (A) Table showing various assembly metrics for Tridacna maxima and Symbiodiniaceae. (B) Density plot of the relative G-C content (\%) for Symbiodiniaceae and Tridacna maxima contigs.

\section{Host clam acclimation response to prolonged high-temperature exposure}

A gene co-expression network was built using the normalized RNA-Seq data from which lowexpression genes had been eliminated, and three modules correlated significantly $(p<0.05)$ with temperature and/or physiological data (including oxygen production, Symbiodiniaceae density and Fv/FM, and host dry weight; Figure S2). No module was correlated with sampling time, $\mathrm{O}_{2}$ consumption, or shell extension. A single host module ( pink $_{\text {host }}$ ) positively correlated with temperature $(\mathrm{R}=0.82)$ and negatively with photosynthetic rate and symbiont density $(\mathrm{R}=-0.52$ and $\mathrm{R}=-$

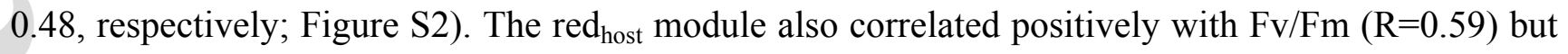
not significantly with temperature $(\mathrm{R}=-0.38 ; p=0.08)$. Among the most enriched $\mathrm{GO}$ terms in the pink $_{\text {host }}$ module were pituitary gland development (GO:0021983), L-ascorbic acid metabolic processes (GO:0019852), regulation of extrinsic apoptotic signaling pathways (GO:2001236), cholesterol efflux (GO:0033344), cilium movement (GO:0003341), and ommochrome biosynthetic processes (GO:0006727). Ommochromes are biological pigments and metabolites of tryptophan (Figon \& Casas, 2019). The red $_{\text {host }}$ module was enriched for cation transport (GO:0006812), neurotransmitter 
uptake (GO:0001504), fructose 6-phosphate metabolic processes (GO:0006002), and reactive oxygen species metabolic processes (GO:0072593). Host module membership eigenvalues were also integrated with the symbiont network analysis (Figure 3), and a complete list of GO-enriched functions has been provided in Table S2.

\section{Acclimation to prolonged high-temperature exposure in Symbiodiniaceae in hospite with clams}

Co-expression network analysis of Symbiodiniaceae showed more modules correlated with temperature than for the clam host, either negatively [midnightblue symbiont $(\mathrm{R}=-0.94)$, blue symbiont $(\mathrm{R}=-$ $0.45)$ ] or positively [cyan symbiont $_{\text {( }}(\mathrm{R}=0.61)$, black symbiont $(\mathrm{R}=0.91)$, yellow symbiont $(\mathrm{R}=0.52)$, and pink $_{\text {symbiont }}(\mathrm{R}=0.85)$; Figure 3]. Among the enriched GO terms in the black symbiont $_{\text {module were RNA }}$ processing (GO:0006396), methylation (GO:0043414), chloroplast-nucleus signaling pathways (GO:0031930), and glycerolipid metabolic processes (GO:0046486). For the cyan symbiont $_{\text {module, }}$ enriched GO terms included response to vitamins (GO:0033273), response to UV-C (GO:0071494), regulation of transferase activity (GO:0051338), intrinsic apoptotic signaling pathways (GO:0097193), and induced systemic resistance (GO:0009682). The yellow symbiont $_{\text {module featured }}$ RNA modification (GO:0009451) and aspartate family amino acid metabolic processes

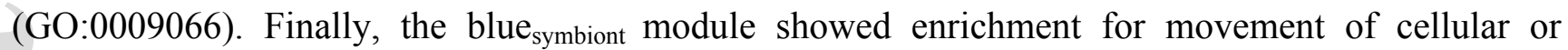
subcellular components (GO:0006928), reproduction (GO:0000003), regulation of cell shape (GO:0008360), oxidation-reduction processes (GO:0055114), and electron transport chain

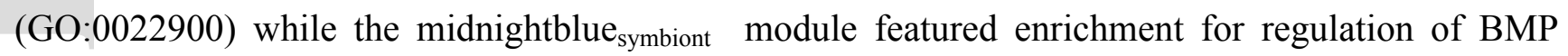
signaling pathways (GO:0030510), hormone biosynthetic processes (GO:0042446), peptidyl-lysine dimethylation (GO:0018027), short-term memory (GO:0007614), and response to red or far, red light (GO:0009639). The complete GO enrichment results can be found in Table S2.

This article is protected by copyright. All rights reserved 


\begin{tabular}{|c|c|c|c|c|c|c|c|c|}
\hline & 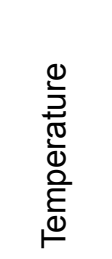 & $\stackrel{\varrho}{\rightleftarrows}$ & $\underset{⿱ 亠 䒑}{\stackrel{\varepsilon}{\rightleftarrows}}$ & $\begin{array}{l}\frac{\overrightarrow{1}}{0} \\
\frac{0}{0} \\
0 \\
0 \\
\text { है } \\
\text { के }\end{array}$ & 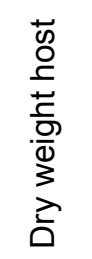 & 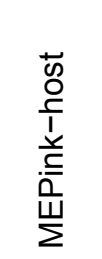 & 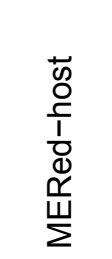 & 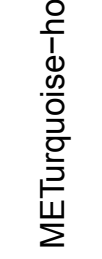 \\
\hline cyan (91) & 0.61 & & -0.66 & & & 0.51 & -0.46 & \\
\hline black $(3,675)$ & 0.91 & & -0.71 & -0.46 & & 0.88 & & \\
\hline yellow $(1,442)$ & 0.52 & & -0.55 & & & 0.47 & -0.51 & \\
\hline $\tan (166)$ & & & & & & & & -0.94 \\
\hline pink (212) & & & & & 0.53 & & & \\
\hline greenyellow (186) & & & 0.54 & & 0.46 & & & \\
\hline blue $(5,414)$ & -0.45 & & 0.52 & & 0.53 & & 0.51 & \\
\hline midnightblue (87) & -0.94 & & 0.73 & & & -0.87 & & \\
\hline
\end{tabular}

Figure 3: Correlation matrix of symbiont gene expression modules against experimental factors (temperature and time), quantitative physiological traits, and module membership (ME) for host modules. Genes have been clustered in modules (y-axis) according to their co-expression values. Values in cells indicate Pearson's correlation scores, and only statistically significant correlations $(p<0.05)$ are depicted.

\section{Multivariate analysis of public Symbiodiniaceae datasets}

We used db-RDA to document gene expression variation in public Symbiodiniaceae datasets [in culture and in hospite with corals and clams (this study)], with temperature and time as the explanatory variables; there was a focus on single-copy orthologs from the genera Cladocopium, Fugacium, and Symbiodinium. The overall model was significant $(p<0.001)$, and the adjusted $\mathrm{R}^{2}$ was 0.12 (Figure 4). Partial db-RDAs showed that temperature also had a significant effect on total gene expression variation across genotypes and experiments (1000 permutations; $F=9.07, p=0.001$ ). A

This article is protected by copyright. All rights reserved 
WGCNA analysis was conducted to identify genes cluster correlated with temperature across all the orthologous genes (Figure S3).

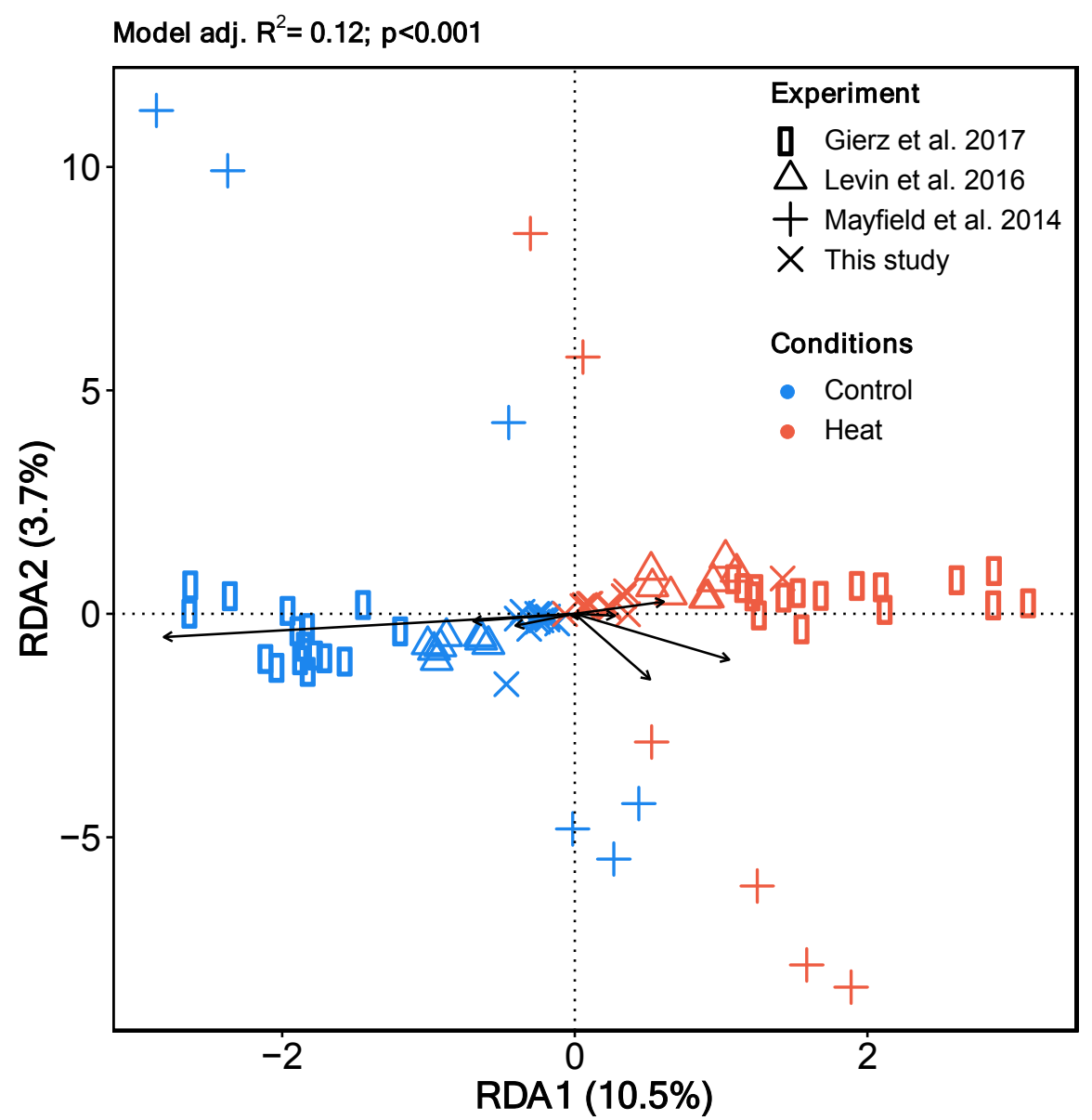

Figure 4: RDA of cultured Symbiodiniaceae (Cladocopium type C1 and Fugacium kawagutii) and in hospite with corals (Cladocopium) and giant clams (Symbiodinium spp.). The reference dataset only included the single-copy orthologous genes across the three genera $(\mathrm{N}=4,187$ orthologs remaining after filtering for residual expression).

\section{Search for thermotolerance-specific genes clusters}

We also conducted independent WGCNA analyses to assess acclimatory responses in cultured Symbiodiniaceae based on the Cladocopium goreaui (formerly type C1) genome (Liu et al., 2018) 
and compared them with thermotolerant phenotypes (Levin et al., 2016). No individual module correlated with time. Instead, we found the majority of the genes to be correlated with temperature, and three modules were uncovered: darkgrey ${ }_{C 1}(R=0.82)$, saddlebrown $_{C 1}(R=-0.89 ; \mathrm{N}=1,354)$, and orange $_{\mathrm{c} 1}(\mathrm{R}=-0.87 ; \mathrm{N}=378$; Figure $\mathrm{S} 4)$. We also found three modules (darkolivegreen $\mathrm{Cl}_{\mathrm{C}}$, lightgreen $_{\mathrm{C} 1}$, and white $\left._{\mathrm{C} 1}\right)$ that were significantly correlated with thermotolerance $(\mathrm{R}=-0.74,-0.99$, and 0.98 , respectively; Figure S4) but not temperature. These modules effectively differentiated thermosensitive Symbiodiniaceae from thermotolerant C1 phenotypes described in Levin et al. (2016). Among the most enriched GO terms for lightgreen ${ }_{\mathrm{c} 1}$ were cellular response to amino acid stimulus (GO:0071230), DNA methylation (GO:0006306), and genetic imprinting (GO:0071514; Figure S4 and Table S2). Furthermore, we found that impact on methylation-associated biological processes [methylation (GO:0032259) and macromolecule methylation (GO:0043414)] was conserved in the lightgreen $_{\mathrm{C} 1}$ module and the response to temperature of symbionts in hospite with clams (black $\mathrm{symb}_{\mathrm{s}}$ module; Figure S5).

\section{Discussion}

Temperature increases are threatening marine invertebrate populations worldwide, especially for species already living at, or close to, their upper thermal tolerance limits (Hoffmann \& Sgrò, 2011). Recent heat wave events have resulted in $\sim 90 \%$ declines in T. maxima populations in some atolls of French Polynesia (Andréfouët et al., 2013, 2017). While several studies have investigated the invertebrate (mollusc and cnidarian) response to heat stress over short-term timescales, relatively few have investigated the prolonged response to elevated temperatures (e.g., Mayfield et al., 2014). Although our clam samples ultimately acclimated to an experimentally elevated temperatures of nearly $31^{\circ} \mathrm{C}$, Symbiodiniaceae density was reduced in thermally challenged clams, and both host clams and their Symbiodiniaceae populations underwent gene expression changes over the course of this two-month experiment. Upon discussing such temperature-driven changes in gene expression, we

This article is protected by copyright. All rights reserved 
highlight some intrinsic responses of the symbionts (i.e., independent of the host species) and identify key mechanisms potentially underlying their thermal-tolerance.

\section{Genus-specific fidelity in clam hosts might preclude symbiont community shifts/shuffling as a thermal acclimation strategy}

A $1.5^{\circ} \mathrm{C}$ temperature elevation over a 65 -day period was sufficient to induce a significant reduction in symbiont density in clams; no bleaching (even partial) was observed in control temperature clams. Our results support previous studies of corals and giant clams in which hightemperature exposure led to sub-lethal bleaching (Ainsworth, Hoegh-Guldberg, Heron, Skirving, \& Leggat, 2008; Brahmi et al., 2019; Hoegh-Guldberg \& Smith, 1989; Jones, Hoegh-Guldberg, Larkum, \& Schreiber, 1998; Leggat et al., 2003; Warner, Fitt, \& Schmidt, 1999; Zhou et al., 2018); whether the cellular mechanisms of bleaching are conserved between corals and giant clams remains to be determined (Mies et al., 2017; Zhou et al., 2018).

For some coral species, resilience to heat stress is associated with a more flexible symbiotic association (i.e., the capacity to shift from one dominant Symbiodiniaceae genus to another) (Hume et al., 2015; LaJeunesse et al., 2004; Putnam, Stat, Pochon, \& Gates, 2012; Rowan, 2004; Silverstein, Correa, \& Baker, 2012). Indeed, some bleaching events have largely been attributed to the thermal sensitivity of specific endosymbiotic Symbiodiniaceae residing in coral host tissues (Berkelmans \& van Oppen, 2006; Oliver \& Palumbi, 2011). Corals hosting Cladocopium spp. (formerly clade C) are typically more prone to bleaching, whereas those housing certain lineages of Durusdinium (formerly clade D) have demonstrated enhanced thermotolerance (Baker, 2003; Mieog, van Oppen, Cantin, Stam, \& Olsen, 2007). Interestingly, Cladocopium spp. and/or Durusdinium spp. are more commonly found in giant clams inhabiting warmer environments while Symbiodinium spp. (formerly clade A) are more common in clams located in cooler waters (DeBoer et al., 2012). Herein, the Symbiodiniaceae communities were predominantly composed of Symbiodinium spp., even after two months of high-temperature exposure; this finding aligns with other studies in corals that found Symbiodiniaceae assemblages to be temporally stable, even as environmental conditions changed (Goulet, 2006; Sampayo, Ridgway, Bongaerts, \& Hoegh-Guldberg, 2008; Thornhill, LaJeunesse, Kemp, Fitt, \& Schmidt, 2006; Thornhill, Xiang, Fitt, \& Santos, 2009). This was not an artifact due to 
the experimental conditions enacted since individuals sampled from their original locations in situ also predominantly host Symbiodinium spp. (i.e., clade A).

Such a high proportion of Symbiodinium spp. in giant clams was expected, and it has also been reported in the sea anemone Anemonia viridis; however, it is in sharp contrast with other invertebrate hosts such as corals, which host a broader Symbiodiniaceae diversity (Manning \& Gates, 2008; Rouzé et al., 2017; Stat, Carter, \& Hoegh-Guldberg, 2006). This near-exclusive hosting of Symbiodinium spp. in clams, and the temporal stability of their association, suggests that some selection process favors this dinoflagellate lineage (or else impairs recruitment of others); lectin/glycan interactions were once thought to play a role, possibly in the primary recognition-related processes (WoodCharlson, Hollingsworth, Krupp, \& Weis, 2006), though this hypothesis has recently been called into question (Parkinson et al., 2018). Admittedly, broader in situ clam sampling, (e.g., encompassing different times of the year) will be necessary to verify the fidelity between Symbiodinium spp. and giant clams, and whether mixed-genera assemblages are common in situ (DeBoer et al., 2012; Parkinson, Banaszak, Altman, LaJeunesse, \& Baums, 2015). The presumably low flexibility would appear to preclude community shifts as a strategy for these clams to cope with increased temperatures, at least in our experimental context. Rather than adaptation (i.e., a community shift resulting in a new "holobiont genomic landscape"), acclimation (i.e., physiological changes that initially manifested at the molecular level) appears to have played a larger role in this study.

\section{Effect of prolonged exposure to elevated temperature on the clam transcriptome}

Both host clam and Symbiodiniaceae gene expression were affected by elevated temperature exposure, with no significant effects of time from 29 days onwards; the temperature-related differences were from thenceforth sustained over time. We found one gene module positively impacted by temperature and negatively correlated with symbiont Fv/Fm and density. This module showed enrichment for ommochrome biosynthesis process and specifically included the tryptophan 2,3-dioxygenase coding gene (TDO), a pivotal regulator of systemic tryptophan levels also involved in the response to oxidative stress (Forrest et al., 2004; Thackray, Mowat, \& Chapman, 2008). Tryptophan is the precursor of 5-hydroxytryptamine (5-HT), a bivalve serotonin transmitter that plays critical roles in numerous physiological functions [e.g., reproduction (Alavi, Nagasawa, Takahashi, \& Osada, 2017)]. In larvae from the coral Orbicella faveolata, TDO (referred to as AGAP) was up-

This article is protected by copyright. All rights reserved 
regulated in response to ultraviolet radiation, and larval fitness (locomotion and settlement) went on to suffer (Aranda et al., 2011). A more thorough understanding, then, of ommochrome biosynthesis and, more generally, tryptophan regulation, is likely to be key to elucidating the molecular regulation of invertebrate-dinoflagellate symbioses, nearly all of which involve at least some degree of nitrogen transfer within holobionts (Chan et al., 2018).

A single module was 1) positively correlated with the maximum dark-adapted yield of photosystem II (Fv/Fm) and 2) enriched for genes encoding proteins involved in glyceraldehyde-3phosphate metabolic processes. Glycerol excretion from dinoflagellate symbionts is largely influenced by the presence of host tissues (Muscatine, 1967). The glyceraldehyde-3-phosphate pathway, which culminates in glycerol production, was also significantly affected by sub-lethal elevated temperature $\left(30^{\circ} \mathrm{C}\right)$ exposure in the reef coral P. damicornis (Mayfield et al., 2014). Pollutant exposure also altered the expression of genes involved in carbohydrate metabolism, albeit only in the coral host compartment (and not in Symbiodiniaceae) in another study (Gust et al., 2014). Admittedly, we did not assess the proportion of energy derived from autotrophy herein, which ranges widely (from 25 to up to $100 \%$ ) and is dependent on the species and/or life history stage in the Tridacna genus (Fisher, Fitt, \& Trench, 1985; Klumpp et al., 1992; Klumpp \& Griffiths, 1994); shifts from autotrophy to heterotrophy, and vice versa, are likely to affect host gene expression patterns. All that can be stated at present is that regulation of tryptophan levels and impairment of carbohydrate metabolism might be key elements in the long-term response to elevated temperature in clams; indeed, these two processes could be inter-linked. However, how these changes would affect finescale interactions between the host and symbionts remains to be explored and should be the focus of future studies of clam-Symbiodiniaceae symbioses.

\section{The response of Symbiodiniaceae dinoflagellates in hospite with clams to prolonged elevated temperature exposure}

Overall, gene clusters of Symbiodiniaceae showed positive correlation between expression levels and prolonged elevated temperature exposure, and some of the modules were also correlated with the lower Symbiodiniaceae Fv/Fm and cell densities documented at elevated temperatures. Other physiological studies have also shown that high temperatures lead to diminished photosynthetic yield in several clades of Symbiodiniaceae (Grégoire, Schmacka, Coffroth, \& Karsten, 2017). In terms of

This article is protected by copyright. All rights reserved 
the RNA-Seq data, genes encoding proteins involved in nitrogen metabolism were significantly affected by high-temperature exposure, and this module correlated with host tryptophan dehydrogenase activity. Interestingly, this GO includes the salt- and drought-induced ring finger1 (SDIR 1)-coding gene known in plants to control abscisic acid (ABA) signal transduction (Zhang et al., 2007), a process that has never before been reported in Symbiodiniaceae. The phytohormone ABA and ROS regulating/modulating proteins are key molecular constituents involved in the capacity to acclimate to abiotic stressors, including oxidative stress tolerance in unicellular algae $(\mathrm{Lu} \mathrm{\&} \mathrm{Xu}$, 2015). Furthermore, up-regulation of ABA signaling genes is associated with a later increase in ABA biosynthesis in several plant species (Vishwakarma et al., 2017). The role of ABA signaling in the thermo-adaptation of Symbiodiniaceae dinoflagellates may consequently be a fruitful avenue for future research.

Herein we also found that expression of genes encoding certain components of the photosynthetic machinery, especially photosystem II (PSII), was dampened at elevated temperature. PSII integrity is vital for proper Symbiodiniaceae function, and PSII damage has been directly linked to bleaching in corals (Warner et al., 1999). It is noteworthy that the same gene module also included chloroplast thylakoid membrane rearrangement-related genes, which are used by Symbiodiniaceae and other photosynthetic organisms to cope with heat and high UV radiation (Sharkey, 2005; Slavov et al., 2016). Although the clam-dinoflagellate holobionts generally appeared to have acclimated to elevated temperatures over our two-month experiment (no large-scale bleaching), the Symbiodiniaceae communities, then, showed signs of intracellular stress given these gene expression changes, as well as the decreases in cell density and Fv/Fm. Whether or not these holobionts could have sustained an even longer exposure to $\sim 31^{\circ} \mathrm{C}$ remains to be determined, though it is worth noting that, unlike in situ, clams were not fed in the aquaria. It is thus likely that clams allowed to feed both autotrophically and heterotrophically might, then, have an even superior capacity for high-temperature acclimation.

\section{Conserved response to high temperatures across Symbiodiniaceae genera and molecular mechanisms linked to thermo-acclimation capacity}

We documented a conserved response to long-term exposure to elevated temperature across Symbiodiniaceae genera based only on orthologous genes, which is noteworthy given the large evolutionary distance between genera (Correa \& Baker, 2009; LaJeunesse, 2001). This common 
response, which transcended the host effect, included genes involved in regulation of the DNA damage response, wound healing and low-temperature responses, chromatin remodeling, mRNA splicing, regulation of lipid biosynthetic processes, and motile cilium assembly. Our results, however, most likely underestimate the molecular complexity of thermo-acclimation given our use of exclusively "single-to-single" orthologous genes. It is also possible that there are holobiont-specific responses that were not explored or detected herein with our bioinformatics approach. For instance, recent studies have shown that the Symbiodiniaceae diverged, in part, in relation to their capacity for synthesizing UV-absorbing mycosporine-like amino acids (Shoguchi et al., 2013). Furthermore, while UV-B radiation in cultured Symbiodiniaceae drastically reduces photosynthetic output, such is not always observed for cells in hospite with clams since the clam hosts produce UV-absorbing proteins (Ishikura, Kato, \& Maruyama, 1997).

We further explored basal differences within the Cladocopium genus that would differentiate the contrastingly thermotolerant phenotypes. We found that differences between thermotolerant phenotypes were driven by molecular pathways uncovered previously (Levin et al., 2016), including meiotic nuclear division and glutathione disulfide oxidoreductase activity; expression of genes involved in photosynthesis, cellular heat acclimation, and methylation programming also differed across gradients of thermotolerance. Regarding the latter, epigenetic landscape rearrangement has been shown to play a role in transgenerational inheritance of thermo-tolerance of various plant models (Bruce, Matthes, Napier, \& Pickett, 2007). Here, thermotolerance-associated modules generally did not correlate with temperature, suggesting that phenotypes have intrinsic gene expression signatures that respond differentially to changes in temperature. It is known that in plants DNA methylation and histone modification are associated with the response to heat stress, and, more specifically, act to prevent heat-associated macromolecular damage (Liu, Feng, Li, \& He, 2015). Such methylation changes might be inherited and account for, at least in part, the remarkable ability of plants to adapt and/or acclimate quickly to stressful environments (Ganguly, Crisp, Eichten, \& Pogson, 2017; Lämke \& Bäurle, 2017).

\section{Conclusions}

This article is protected by copyright. All rights reserved 
The co-expression network analysis proved to be a powerful tool for dissecting compartmentspecific transcriptomic responses in symbiotic systems. This is especially true when looking for acclimatory signatures that, in contrast to short-term stress responses, are characterized by rather subtle changes over longer periods. Indeed, our data from a long-term high temperature study revealed that different cellular processes are impacted in the host clam and in hospite Symbiodiniaceae compartments; genes encoding key photosynthesis proteins were particularly temperature sensitive in not only Symbiodiniaceae in hospite, but also in culture. Future studies focusing on the range of optimal thermal conditions of the T. maxima species may improve our understanding on the thermal tolerance of the clams and their symbionts. Although the giant clams used in this study ultimately survived a two-month exposure to nearly $31^{\circ} \mathrm{C}$, it is possible that slightly higher temperatures, or extended exposure times, might cause them to bleach to such a great extent that they would not survive. Regardless, our data show that novel mechanisms involving epigenetic landscape rearrangement are associated with elevated Symbiodiniaceae thermotolerance. How the impact of stressful environmental conditions might impact the subsequent generation's tolerance and/or physiological capacities (i.e., epigenetic effects) must consequently be addressed in the near future.

\section{References}

Addessi, L. (2001). Giant clam bleaching in the lagoon of Takapoto atoll (French Polynesia). Coral Reefs, 19(3), 220-220. https://doi.org/10.1007/PL00006957

Ainsworth, T. D., Hoegh-Guldberg, O., Heron, S. F., Skirving, W. J., \& Leggat, W. (2008). Early cellular changes are indicators of pre-bleaching thermal stress in the coral host. Journal of Experimental Marine Biology and Ecology, 364(2), 63-71. https://doi.org/10.1016/j.jembe.2008.06.032

Alavi, S. M. H., Nagasawa, K., Takahashi, K. G., \& Osada, M. (2017). Structure-function of serotonin in bivalve molluscs. In K. F. Shad (Ed.), Serotonin - A Chemical Messenger Between All Types of Living Cells. https://doi.org/10.5772/intechopen.69165

Anders, S., Pyl, P. T., \& Huber, W. (2015). HTSeq-a Python framework to work with high- 
throughput $\quad$ sequencing data. Bioinformatics, $\quad 31(2), \quad$ 166-169. https://doi.org/10.1093/bioinformatics/btu638

Andréfouët, S., Van Wynsberge, S., Gaertner-Mazouni, N., Menkes, C., Gilbert, A., \& Remoissenet, G. (2013). Climate variability and massive mortalities challenge giant clam conservation and management efforts in French Polynesia atolls. Biological Conservation, 160, 190-199. https://doi.org/10.1016/j.biocon.2013.01.017

Andréfouët, S., Wynsberge, S. V., Kabbadj, L., Wabnitz, C. C. C., Menkes, C., Tamata, T., ... Remoissenet, G. (2017). Adaptive management for the sustainable exploitation of lagoon resources in remote islands: lessons from a massive El Niño-induced giant clam bleaching event in the Tuamotu atolls (French Polynesia). Environmental Conservation, 1-11. https://doi.org/10.1017/S0376892917000212

Aranda, M., Banaszak, A. T., Bayer, T., Luyten, J. R., Medina, M., \& Voolstra, C. R. (2011). Differential sensitivity of coral larvae to natural levels of ultraviolet radiation during the onset of larval competence. Molecular Ecology, 20(14), 2955-2972. https://doi.org/10.1111/j.1365294X.2011.05153.X

Baillie, B. K., Belda-Baillie, C. A., \& Maruyama, T. (2000). Conspecificity and Indo-Pacific distribution of Symbiodinium genotypes (Dinophyceae) from giant clams. Journal of Phycology, 36(6), 1153-1161. https://doi.org/10.1046/j.1529-8817.2000.00010.x

Baker, A. C. (2003). Flexibility and Specificity in Coral-Algal Symbiosis: Diversity, Ecology, and Biogeography of Symbiodinium. Annual Review of Ecology, Evolution, and Systematics, 34(1), 661689. https://doi.org/10.1146/annurev.ecolsys.34.011802.132417

Barshis, D. J., Ladner, J. T., Oliver, T. A., \& Palumbi, S. R. (2014). Lineage-Specific Transcriptional Profiles of Symbiodinium spp. Unaltered by Heat Stress in a Coral Host. Molecular Biology and Evolution, 31(6), 1343-1352. https://doi.org/10.1093/molbev/msu107

Barshis, D. J., Ladner, J. T., Oliver, T. A., Seneca, F. O., Traylor-Knowles, N., \& Palumbi, S. R. (2013). Genomic basis for coral resilience to climate change. Proceedings of the National Academy of Sciences, 110(4), 1387-1392.

Berkelmans, R., \& van Oppen, M. J. H. (2006). The role of zooxanthellae in the thermal tolerance of corals: a "nugget of hope" for coral reefs in an era of climate change. Proceedings of the Royal 
Society B: Biological Sciences, 273(1599), 2305-2312. https://doi.org/10.1098/rspb.2006.3567

Bokulich, N. A., Kaehler, B. D., Rideout, J. R., Dillon, M., Bolyen, E., Knight, R., ... Gregory Caporaso, J. (2018). Optimizing taxonomic classification of marker-gene amplicon sequences with QIIME 2's q2-feature-classifier plugin. Microbiome, 6(1). https://doi.org/10.1186/s40168-018-0470-z Bolger, A. M., Lohse, M., \& Usadel, B. (2014). Trimmomatic: a flexible trimmer for Illumina sequence data. Bioinformatics, 30(15), 2114-2120. https://doi.org/10.1093/bioinformatics/btu170 Brahmi, Chloé, Le Moullac, G., Soyez, C., Beliaeff, B., Lazareth, C. E., Gaertner-Mazouni, N., \& Vidal-Dupiol, J. (2019). Effects of temperature and $\mathrm{p} \mathrm{CO}_{2}$ on the respiration, biomineralization and photophysiology of the giant clam Tridacna maxima. https://doi.org/10.1101/672907

Brahmi, Chloe, Le Moullac, G., Soyez, C., Chapron, L., Gaertner-Mazouni, N., \& Vidal-Dupiol, J. (2019). Effects of temperature and $\mathrm{pH}$ on the respiration, biomineralization and photophysiology of the giant clam Tridacna maxima. BioRxiv.

Bruce, T. J. A., Matthes, M. C., Napier, J. A., \& Pickett, J. A. (2007). Stressful “memories” of plants: Evidence and possible mechanisms. Plant Science, 173(6), 603-608. https://doi.org/10.1016/j.plantsci.2007.09.002

Buck, B. (2002). Effect of increased irradiance and thermal stress on the symbiosis of Symbiodinium microadriaticum and Tridacna gigas. Aquatic Living Resources, 15(2), 107-117. https://doi.org/10.1016/S0990-7440(02)01159-2

Callahan, B. J., McMurdie, P. J., Rosen, M. J., Han, A. W., Johnson, A. J. A., \& Holmes, S. P. (2016). DADA2: High resolution sample inference from Illumina amplicon data. Nature Methods, 13(7), 581-583. https://doi.org/10.1038/nmeth.3869

Chan, C. Y. L., Hiong, K. C., Boo, M. V., Choo, C. Y. L., Wong, W. P., Chew, S. F., \& Ip, Y. K. (2018). Light exposure enhances urea absorption in the fluted giant clam, Tridacna squamosa, and up-regulates the protein abundance of a light-dependent urea active transporter, DUR3-like, in its ctenidium. Journal of Experimental Biology, 221(8), jeb176313. https://doi.org/10.1242/jeb.176313

Correa, A. M. S., \& Baker, A. C. (2009). Understanding diversity in coral-algal symbiosis: a clusterbased approach to interpreting fine-scale genetic variation in the genus Symbiodinium. Coral Reefs, 28(1), 81-93. https://doi.org/10.1007/s00338-008-0456-6

Crowder, C. M., Meyer, E., Fan, T.-Y., \& Weis, V. M. (2017). Impacts of temperature and lunar day

This article is protected by copyright. All rights reserved 
on gene expression profiles during a monthly reproductive cycle in the brooding coral Pocillopora damicornis. Molecular Ecology, 26(15), 3913-3925. https://doi.org/10.1111/mec.14162

Cunning, R., Gates, R. D., \& Edmunds, P. J. (2017). Using high-throughput sequencing of ITS2 to describe Symbiodinium metacommunities in St. John, U.S. Virgin Islands (No. e2925v1). Retrieved from PeerJ Preprints website: https://peerj.com/preprints/2925

DeBoer, T., Baker, A., Erdmann, M., Ambariyanto, Jones, P., \& Barber, P. (2012). Patterns of Symbiodinium distribution in three giant clam species across the biodiverse Bird's Head region of Indonesia. Marine Ecology Progress Series, 444, 117-132. https://doi.org/10.3354/meps09413

Dubousquet, V., Gros, E., Berteaux-Lecellier, V., Viguier, B., Raharivelomanana, P., Bertrand, C., \& Lecellier, G. J. (2016). Changes in fatty acid composition in the giant clam Tridacna maxima in response to thermal stress. Biology Open, 5(10), 1400-1407. https://doi.org/10.1242/bio.017921

Emms, D. M., \& Kelly, S. (2015). OrthoFinder: solving fundamental biases in whole genome comparisons dramatically improves orthogroup inference accuracy. Genome Biology, 16(1), 157. https://doi.org/10.1186/s13059-015-0721-2

Figon, F., \& Casas, J. (2019). Ommochromes in invertebrates: biochemistry and cell biology: Ommochromes in invertebrates. Biological Reviews, 94(1), 156-183. https://doi.org/10.1111/brv.12441

Fisher, C. R., Fitt, W. K., \& Trench, R. K. (1985). Photosynthesis and respiration in Tridacna gigas as a function of irradiance and size. The Biological Bulletin, 169(1), 230-245. https://doi.org/10.2307/1541400

Fitt, W., Brown, B., Warner, M., \& Dunne, R. (2001). Coral bleaching: interpretation of thermal tolerance limits and thermal thresholds in tropical corals. Coral Reefs, 20(1), 51-65. https://doi.org/10.1007/s003380100146

Forrest, C. M., Mackay, G. M., Stoy, N., Egerton, M., Christofides, J., Stone, T. W., \& Darlington, L. G. (2004). Tryptophan Loading Induces Oxidative Stress. Free Radical Research, 38(11), 1167-1171. https://doi.org/10.1080/10715760400011437

Ganguly, D. R., Crisp, P. A., Eichten, S. R., \& Pogson, B. J. (2017). The Arabidopsis DNA methylome is stable under transgenerational drought stress. Plant Physiology, 175(4), 1893-1912. https://doi.org/10.1104/pp.17.00744

This article is protected by copyright. All rights reserved 
Gierz, S. L., Forêt, S., \& Leggat, W. (2017). Transcriptomic analysis of thermally stressed Symbiodinium reveals differential expression of stress and metabolism genes. Frontiers in Plant Science, 8. https://doi.org/10.3389/fpls.2017.00271

Gilbert, A., Yan, L., Remoissenet, G., Andréfouët, S., Payri, C., \& Chancerelle, Y. (2005). Extraordinarily high giant clam density under protection in Tatakoto atoll (Eastern Tuamotu archipelago, French Polynesia). Coral Reefs, 24(3), 495-495. https://doi.org/10.1007/s00338-0050494-2

Gilbert, Antoine, Remoissenet, G., Yan, L., \& Andrefouet, S. (2006). Special traits and promises of the giant clam (Tridacna maxima) in French Polynesia. Fisheries Newsletter-South Pacific Commission, 118, 44.

González-Pech, R. A., Ragan, M. A., \& Chan, C. X. (2017). Signatures of adaptation and symbiosis in genomes and transcriptomes of Symbiodinium. Scientific Reports, 7(1). https://doi.org/10.1038/s41598-017-15029-w

Goulet, T. (2006). Most corals may not change their symbionts. Marine Ecology Progress Series, 321, 1-7. https://doi.org/10.3354/meps321001

Grégoire, V., Schmacka, F., Coffroth, M. A., \& Karsten, U. (2017). Photophysiological and thermal tolerance of various genotypes of the coral endosymbiont Symbiodinium sp. (Dinophyceae). Journal of Applied Phycology, 29(4), 1893-1905. https://doi.org/10.1007/s10811-017-1127-1

Gust, K. A., Najar, F. Z., Habib, T., Lotufo, G. R., Piggot, A. M., Fouke, B. W., ... Perkins, E. J. (2014). Coral-zooxanthellae meta-transcriptomics reveals integrated response to pollutant stress. BMC Genomics, 15(1), 591. https://doi.org/10.1186/1471-2164-15-591

Haas, B. J., Papanicolaou, A., Yassour, M., Grabherr, M., Blood, P. D., Bowden, J., ... Regev, A. (2013). De novo transcript sequence reconstruction from RNA-seq using the Trinity platform for reference generation and analysis. Nature Protocols, 8(8), 1494-1512. https://doi.org/10.1038/nprot.2013.084

Hawkins, A. J. S., \& Klumpp, D. W. (1995). Nutrition of the giant clam Tridacna gigas (L.). II. Relative contributions of filter-feeding and the ammonium-nitrogen acquired and recycled by symbiotic alga towards total nitrogen requirements for tissue growth and metabolism. Journal of Experimental Marine Biology and Ecology, 190(2), 263-290. https://doi.org/10.1016/0022- 
0981(95)00044-R

Hoegh-Guldberg, O., Mumby, P. J., Hooten, A. J., Steneck, R. S., Greenfield, P., Gomez, E., ... Hatziolos, M. E. (2007). Coral Reefs Under Rapid Climate Change and Ocean Acidification. Science, 318(5857), 1737-1742. https://doi.org/10.1126/science.1152509

Hoegh-Guldberg, Ove, \& Smith, G. J. (1989). The effect of sudden changes in temperature, light and salinity on the population density and export of zooxanthellae from the reef corals Stylophora pistillata Esper and Seriatopora hystrix Dana. Journal of Experimental Marine Biology and Ecology, 129(3), 279-303. https://doi.org/10.1016/0022-0981(89)90109-3

Hoffmann, A. A., \& Sgrò, C. M. (2011). Climate change and evolutionary adaptation. Nature, 470(7335), 479-485. https://doi.org/10.1038/nature09670

Holt, A. L., Vahidinia, S., Gagnon, Y. L., Morse, D. E., \& Sweeney, A. M. (2014). Photosymbiotic giant clams are transformers of solar flux. Journal of The Royal Society Interface, 11(101), 20140678. https://doi.org/10.1098/rsif.2014.0678

Hou, J., Xu, T., Su, D., Wu, Y., Cheng, L., Wang, J., ... Wang, Y. (2018). RNA-Seq reveals extensive transcriptional response to heat stress in the stony coral Galaxea fascicularis. Frontiers in Genetics, 9. https://doi.org/10.3389/fgene.2018.00037

Hughes, T. P., Baird, A. H., Bellwood, D. R., Card, M., Connolly, S. R., Folke, C., ... Roughgarden, J. (2003). Climate change, human impacts, and the resilience of coral reefs. Science, 301(5635), 929933. https://doi.org/10.1126/science.1085046

Hume, B. C. C., D’Angelo, C., Smith, E. G., Stevens, J. R., Burt, J., \& Wiedenmann, J. (2015). Symbiodinium thermophilum sp. nov., a thermotolerant symbiotic alga prevalent in corals of the world's hottest sea, the Persian/Arabian Gulf. Scientific Reports, 5, 8562.

Ikeda, S., Yamashita, H., Kondo, S., Inoue, K., Morishima, S., \& Koike, K. (2017). Zooxanthellal genetic varieties in giant clams are partially determined by species-intrinsic and growth-related characteristics. PLOS ONE, 12(2), e0172285. https://doi.org/10.1371/journal.pone.0172285

Ishikura, M., Kato, C., \& Maruyama, T. (1997). UV-absorbing substances in zooxanthellate and azooxanthellate clams. Marine Biology, 128(4), 649-655. https://doi.org/10.1007/s002270050131

Jantzen, C., Wild, C., El-Zibdah, M., Roa-Quiaoit, H. A., Haacke, C., \& Richter, C. (2008). Photosynthetic performance of giant clams, Tridacna maxima and T. squamosa, Red Sea. Marine

This article is protected by copyright. All rights reserved 
Biology, 155(2), 211-221. https://doi.org/10.1007/s00227-008-1019-7

Jones, R. J., Hoegh-Guldberg, O., Larkum, A. W. D., \& Schreiber, U. (1998). Temperature-induced bleaching of corals begins with impairment of the $\mathrm{CO} 2$ fixation mechanism in zooxanthellae. Plant, Cell and Environment, 21(12), 1219-1230. https://doi.org/10.1046/j.1365-3040.1998.00345.x

Kenkel, C. D., \& Matz, M. V. (2016). Gene expression plasticity as a mechanism of coral adaptation to a variable environment. Nature Ecology \& Evolution, 1(1), 0014. https://doi.org/10.1038/s41559016-0014

Klumpp, D. W., Bayne, B. L., \& Hawkins, A. J. S. (1992). Nutrition of the giant clam Tridacna gigas (L.) I. Contribution of filter feeding and photosynthates to respiration and growth. Journal of Experimental Marine Biology and Ecology, 155(1), 105-122. https://doi.org/10.1016/00220981(92)90030-E

Klumpp, D. W., \& Griffiths, C. L. (1994). Contributions of phototrophic and heterotrophic nutrition to the metabolic and growth requirements of four species of giant clam (Tridacnidae). Marine Ecology Progress Series, 115(1/2), 103-115.

Ladner, J. T., Barshis, D. J., \& Palumbi, S. R. (2012). Protein evolution in two co-occurring types of Symbiodinium: an exploration into the genetic basis of thermal tolerance in Symbiodinium clade D. BMC Evolutionary Biology, 12(1), 217. https://doi.org/10.1186/1471-2148-12-217

LaJeunesse, T. C. (2001). Investigating the biodiversity, ecology, and phylogeny of endosymbiotic dinoflagellates in the genus Symbiodinium using the ITS region: in search of a "species" level marker. Journal of Phycology, 37(5), 866-880. https://doi.org/10.1046/j.1529-8817.2001.01031.x

LaJeunesse, T. C., Parkinson, J. E., Gabrielson, P. W., Jeong, H. J., Reimer, J. D., Voolstra, C. R., \& Santos, S. R. (2018). Systematic Revision of Symbiodiniaceae Highlights the Antiquity and Diversity of Coral Endosymbionts. Current Biology, 28(16), 2570-2580.e6. https://doi.org/10.1016/j.cub.2018.07.008

LaJeunesse, ToddC., Thornhill, DanielJ., Cox, EvelynF., Stanton, FrankG., Fitt, WilliamK., \& Schmidt, GregoryW. (2004). High diversity and host specificity observed among symbiotic dinoflagellates in reef coral communities from Hawaii. Coral Reefs, 23(4), 596-603. https://doi.org/10.1007/s00338-004-0428-4

Lämke, J., \& Bäurle, I. (2017). Epigenetic and chromatin-based mechanisms in environmental stress

This article is protected by copyright. All rights reserved 
adaptation and stress memory in plants. Genome Biology, 18(1). https://doi.org/10.1186/s13059-0171263-6

Langfelder, P., \& Horvath, S. (2008). WGCNA: an R package for weighted correlation network analysis. BMC Bioinformatics, 9, 559. https://doi.org/10.1186/1471-2105-9-559

Lee, S. Y., Jeong, H. J., Kang, N. S., Jang, T. Y., Jang, S. H., \& Lajeunesse, T. C. (2015). Symbiodinium tridacnidorum sp. nov., a dinoflagellate common to Indo-Pacific giant clams, and a revised morphological description of Symbiodinium microadriaticum Freudenthal, emended Trench \&amp; Blank. European Journal of Phycology, 50(2), 155-172. https://doi.org/10.1080/09670262.2015.1018336

Legendre, P., \& Gallagher, E. D. (2001). Ecologically meaningful transformations for ordination of species data. Oecologia, 129(2), 271-280. https://doi.org/10.1007/s004420100716

Legendre, P., \& legendre, L. (2012). Numerical Ecology, Volume 24 - 3rd Edition. Elsevier.

Leggat, W., Buck, B. H., Grice, A., \& Yellowlees, D. (2003). The impact of bleaching on the metabolic contribution of dinoflagellate symbionts to their giant clam host. Plant, Cell and Environment, 26(12), 1951-1961. https://doi.org/10.1046/j.0016-8025.2003.01111.x

Levin, R. A., Beltran, V. H., Hill, R., Kjelleberg, S., McDougald, D., Steinberg, P. D., \& van Oppen, M. J. H. (2016). Sex, scavengers, and chaperones: transcriptome secrets of divergent Symbiodinium thermal tolerances. Molecular Biology and Evolution, 33(9), 2201-2215. https://doi.org/10.1093/molbev/msw119

Liu, H., Stephens, T. G., González-Pech, R. A., Beltran, V. H., Lapeyre, B., Bongaerts, P., ... Chan, C. X. (2018). Symbiodinium genomes reveal adaptive evolution of functions related to coraldinoflagellate symbiosis. Communications Biology, 1(1). https://doi.org/10.1038/s42003-018-0098-3

Liu, J., Feng, L., Li, J., \& He, Z. (2015). Genetic and epigenetic control of plant heat responses. Frontiers in Plant Science, 06. https://doi.org/10.3389/fpls.2015.00267

Love, M. I., Huber, W., \& Anders, S. (2014). Moderated estimation of fold change and dispersion for RNA-seq data with DESeq2. Genome Biology, 15(12), 550. https://doi.org/10.1186/s13059-014-05508

Lu, Y., \& Xu, J. (2015). Phytohormones in microalgae: a new opportunity for microalgal biotechnology? Trends in Plant Science, 20(5), 273-282. https://doi.org/10.1016/j.tplants.2015.01.006

This article is protected by copyright. All rights reserved 
Lucas, J. S. (1994). The biology, exploitation, and mariculture of giant clams (Tridacnidae). Reviews in Fisheries Science, 2(3), 181-223. https://doi.org/10.1080/10641269409388557

Manning, M. M., \& Gates, R. D. (2008). Diversity in populations of free-living Symbiodinium from a Caribbean and Pacific reef. Limnology and Oceanography, 53(5), 1853-1861. https://doi.org/10.4319/lo.2008.53.5.1853

Mayfield, A. B., Wang, Y.-B., Chen, C.-S., Lin, C.-Y., \& Chen, S.-H. (2014). Compartment-specific transcriptomics in a reef-building coral exposed to elevated temperatures. Molecular Ecology, 23(23), 5816-5830. https://doi.org/10.1111/mec.12982

Menoud, M., Van Wynsberge, S., Moullac, G. L., Levy, P., Andréfouët, S., Remoissenet, G., \& Gaertner-Mazouni, N. (2016). Identifying robust proxies of gonad maturation for the protandrous hermaphrodite Tridacna maxima (Röding, 1798, Bivalvia) from individual to population scale. Journal of Shellfish Research, 35(1), 51-61. https://doi.org/10.2983/035.035.0107

Mieog, J. C., van Oppen, M. J. H., Cantin, N. E., Stam, W. T., \& Olsen, J. L. (2007). Real-time PCR reveals a high incidence of Symbiodinium clade $D$ at low levels in four scleractinian corals across the Great Barrier Reef: implications for symbiont shuffling. Coral Reefs, 26(3), 449-457. https://doi.org/10.1007/s00338-007-0244-8

Mies, M., Voolstra, C. R., Castro, C. B., Pires, D. O., Calderon, E. N., \& Sumida, P. Y. G. (2017). Expression of a symbiosis-specific gene in Symbiodinium type A1 associated with coral, nudibranch and giant clam larvae. Royal Society Open Science, 4(5), 170253. https://doi.org/10.1098/rsos.170253 Mies, Miguel, Van Sluys, M. A., Metcalfe, C. J., \& Sumida, P. Y. G. (2017). Molecular evidence of symbiotic activity between Symbiodinium and Tridacna maxima larvae. Symbiosis, 72(1), 13-22. https://doi.org/10.1007/s13199-016-0433-8

Muscatine, L. (1967). Glycerol excretion by symbiotic algae from corals and Tridacna and its control by the host. Science, 156(3774), 516-519. https://doi.org/10.1126/science.156.3774.516

Norton, J. H., Shepherd, M. A., Long, H. M., \& Fitt, W. K. (1992). The zooxanthellal tubular system in the Giant clam. The Biological Bulletin, 183(3), 503-506. https://doi.org/10.2307/1542028

Oksanen, J., Blanchet, F. G., Kindt, R., Legendre, P., Minchin, P. R., Wagner, R. B. O., ... Wagner, H. (2012). Vegan: community ecology package. R package. Version 2.0-3.

Oliver, T. A., \& Palumbi, S. R. (2011). Many corals host thermally resistant symbionts in high-

This article is protected by copyright. All rights reserved 
temperature habitat. Coral Reefs, 30(1), 241-250. https://doi.org/10.1007/s00338-010-0696-0

Paradis, E., Claude, J., \& Strimmer, K. (2004). APE: Analyses of Phylogenetics and Evolution in R language. Bioinformatics, 20(2), 289-290. https://doi.org/10.1093/bioinformatics/btg412

Parkinson, John E., Tivey, T. R., Mandelare, P. E., Adpressa, D. A., Loesgen, S., \& Weis, V. M. (2018). Subtle Differences in Symbiont Cell Surface Glycan Profiles Do Not Explain SpeciesSpecific Colonization Rates in a Model Cnidarian-Algal Symbiosis. Frontiers in Microbiology, 9. https://doi.org/10.3389/fmicb.2018.00842

Parkinson, John Everett, Banaszak, A. T., Altman, N. S., LaJeunesse, T. C., \& Baums, I. B. (2015). Intraspecific diversity among partners drives functional variation in coral symbioses. Scientific Reports, 5. https://doi.org/10.1038/srep15667

Pinzón, J. H., Devlin-Durante, M. K., Weber, M. X., Baums, I. B., \& LaJeunesse, T. C. (2011). Microsatellite loci for Symbiodinium A3 (S. fitti) a common algal symbiont among Caribbean Acropora (stony corals) and Indo-Pacific giant clams (Tridacna). Conservation Genetics Resources, 3(1), 45-47. https://doi.org/10.1007/s12686-010-9283-5

Pinzón, J. H., Kamel, B., Burge, C. A., Harvell, C. D., Medina, M., Weil, E., \& Mydlarz, L. D. (2015). Whole transcriptome analysis reveals changes in expression of immune-related genes during and after bleaching in a reef-building coral. Royal Society Open Science, 2(4), 140214. https://doi.org/10.1098/rsos.140214

Putnam, H. M., Stat, M., Pochon, X., \& Gates, R. D. (2012). Endosymbiotic flexibility associates with environmental sensitivity in scleractinian corals. Proceedings of the Royal Society of London B: Biological Sciences, 279(1746), 4352-4361. https://doi.org/10.1098/rspb.2012.1454

Ritchie, M. E., Phipson, B., Wu, D., Hu, Y., Law, C. W., Shi, W., \& Smyth, G. K. (2015). limma powers differential expression analyses for RNA-sequencing and microarray studies. Nucleic Acids Research, 43(7), e47-e47. https://doi.org/10.1093/nar/gkv007

Rouzé, H., Lecellier, G. J., Saulnier, D., Planes, S., Gueguen, Y., Wirshing, H. H., \& BerteauxLecellier, V. (2017). An updated assessment of Symbiodinium spp. that associate with common scleractinian corals from Moorea (French Polynesia) reveals high diversity among background symbionts and a novel finding of clade B. PeerJ, 5, e2856. https://doi.org/10.7717/peerj.2856

Rowan, R. (2004). Thermal adaptation in reef coral symbionts. Nature, 430, 742.

This article is protected by copyright. All rights reserved 
Rowan, R., Knowlton, N., Baker, A., \& Jara, J. (1997). Landscape ecology of algal symbionts creates variation in episodes of coral bleaching. Nature, 388(6639), 265-269. https://doi.org/10.1038/40843 Sampayo, E. M., Ridgway, T., Bongaerts, P., \& Hoegh-Guldberg, O. (2008). Bleaching susceptibility and mortality of corals are determined by fine-scale differences in symbiont type. Proceedings of the National Academy of Sciences, 105(30), 10444-10449. https://doi.org/10.1073/pnas.0708049105 Sharkey, T. D. (2005). Effects of moderate heat stress on photosynthesis: importance of thylakoid reactions, rubisco deactivation, reactive oxygen species, and thermotolerance provided by isoprene. Plant, Cell and Environment, 28(3), 269-277. https://doi.org/10.1111/j.1365-3040.2005.01324.x Shoguchi, E., Shinzato, C., Kawashima, T., Gyoja, F., Mungpakdee, S., Koyanagi, R., ... Satoh, N. (2013). Draft assembly of the Symbiodinium minutum nuclear genome reveals dinoflagellate gene structure. Current Biology: CB, 23(15), 1399-1408. https://doi.org/10.1016/j.cub.2013.05.062

Silverstein, R. N., Correa, A. M. S., \& Baker, A. C. (2012). Specificity is rarely absolute in coral-algal symbiosis: implications for coral response to climate change. Proceedings of the Royal Society B: Biological Sciences, 279(1738), 2609-2618. https://doi.org/10.1098/rspb.2012.0055

Simão, F. A., Waterhouse, R. M., Ioannidis, P., Kriventseva, E. V., \& Zdobnov, E. M. (2015). BUSCO: assessing genome assembly and annotation completeness with single-copy orthologs. Bioinformatics, 31(19), 3210-3212. https://doi.org/10.1093/bioinformatics/btv351

Slavov, C., Schrameyer, V., Reus, M., Ralph, P. J., Hill, R., Büchel, C., ... Holzwarth, A. R. (2016). "Super-quenching" state protects Symbiodinium from thermal stress - Implications for coral bleaching. Biochimica et Biophysica Acta (BBA) - Bioenergetics, 1857(6), 840-847. https://doi.org/10.1016/j.bbabio.2016.02.002

Soo, P., \& Todd, P. A. (2014). The behaviour of giant clams (Bivalvia: Cardiidae: Tridacninae). Marine Biology, 161(12), 2699-2717. https://doi.org/10.1007/s00227-014-2545-0

Stat, M., Carter, D., \& Hoeghguldberg, O. (2006). The evolutionary history of Symbiodinium and scleractinian hosts-Symbiosis, diversity, and the effect of climate change. Perspectives in Plant Ecology, Evolution and Systematics, 8(1), 23-43. https://doi.org/10.1016/j.ppees.2006.04.001

Thackray, S. J., Mowat, C. G., \& Chapman, S. K. (2008). Exploring the mechanism of tryptophan 2,3-dioxygenase. Biochemical Society Transactions, 36(Pt 6), 1120-1123. https://doi.org/10.1042/BST0361120

This article is protected by copyright. All rights reserved 
Thornhill, D. J., LaJeunesse, T. C., Kemp, D. W., Fitt, W. K., \& Schmidt, G. W. (2006). Multi-year, seasonal genotypic surveys of coral-algal symbioses reveal prevalent stability or post-bleaching reversion. Marine Biology, 148(4), 711-722. https://doi.org/10.1007/s00227-005-0114-2

Thornhill, D. J., Xiang, Y., Fitt, W. K., \& Santos, S. R. (2009). Reef Endemism, Host Specificity and Temporal Stability in Populations of Symbiotic Dinoflagellates from Two Ecologically Dominant Caribbean Corals. PLoS ONE, 4(7), e6262. https://doi.org/10.1371/journal.pone.0006262

Van Wynsberge, S., Andréfouët, S., Gaertner-Mazouni, N., \& Remoissenet, G. (2018). Consequences of an uncertain mass mortality regime triggered by climate variability on giant clam population management in the Pacific Ocean. Theoretical Population Biology, 119, 37-47. https://doi.org/10.1016/j.tpb.2017.10.005

Vishwakarma, K., Upadhyay, N., Kumar, N., Yadav, G., Singh, J., Mishra, R. K., ... Sharma, S. (2017). Abscisic acid signaling and abiotic stress tolerance in plants: a review on current knowledge and future prospects. Frontiers in Plant Science, 8, 161. https://doi.org/10.3389/fpls.2017.00161

Warner, M. E., Fitt, W. K., \& Schmidt, G. W. (1999). Damage to photosystem II in symbiotic dinoflagellates: A determinant of coral bleaching. Proceedings of the National Academy of Sciences, 96(14), 8007-8012. https://doi.org/10.1073/pnas.96.14.8007

Wood-Charlson, E. M., Hollingsworth, L. L., Krupp, D. A., \& Weis, V. M. (2006). Lectin/glycan interactions play a role in recognition in a coral/dinoflagellate symbiosis. Cellular Microbiology, 8(12), 1985-1993. https://doi.org/10.1111/j.1462-5822.2006.00765.x

Wright, R. M., Aglyamova, G. V., Meyer, E., \& Matz, M. V. (2015). Gene expression associated with white syndromes in a reef building coral, Acropora hyacinthus. BMC Genomics, 16(1), 371. https://doi.org/10.1186/s12864-015-1540-2

Wu, T. D., Reeder, J., Lawrence, M., Becker, G., \& Brauer, M. J. (2016). GMAP and GSNAP for genomic sequence alignment: enhancements to speed, accuracy, and functionality. Statistical Genomics: Methods and Protocols, pp. 283-334.

Yamashita, H., Suzuki, G., Hayashibara, T., \& Koike, K. (2011). Do corals select zooxanthellae by alternative discharge? Marine Biology, 158(1), 87-100. https://doi.org/10.1007/s00227-010-1544-z Zhang, Y., Yang, C., Li, Y., Zheng, N., Chen, H., Zhao, Q., ... Xie, Q. (2007). SDIR1 Is a RING Finger E3 Ligase That Positively Regulates Stress-Responsive Abscisic Acid Signaling in 
Arabidopsis. The Plant Cell, 19(6), 1912-1929. https://doi.org/10.1105/tpc.106.048488

Zhou, Z., Liu, Z., Wang, L., Luo, J., \& Li, H. (2018). Oxidative stress, apoptosis activation and symbiosis disruption in giant clam Tridacna crocea under high temperature. Fish \& Shellfish Immunology, 84, 451-457. https://doi.org/10.1016/j.fsi.2018.10.033

\section{Acknowledgments}

General: We are grateful to Michel Pahuatini for providing the "small giant" clams and seawater samples. We thank Claude Soyez and Leila Chapron for their help in animal rearing. We thank Dr. Laetitia Hédouin for valuable comments on prior versions of the manuscript, Corinne Belliard for help with DNA preparation, and Dr. Yu-Bin Wang for making the $P$. damicornis-Symbiodiniaceae transcriptomic resources openly accessible, as well as designing the afore-cited $P$. damicornis-Symbiodiniaceae transcriptome server. Finally, we thank O. Bichet for her help with the figures.

Funding: This experiment was made possible by a grant from Labex CORAIL (France), as well as an IFREMER grant (France; Master's internship to HAM).

Author contributions: $\mathrm{CB}$ and JVD conceived the experimental design, under which tissue samples featured herein were collected. CB and JLL conceived the transcriptomic study. HAM and JLL carried out the laboratory benchwork. HAM and JLL analyzed the data. HAM, CB, $\mathrm{ABM}$, and JLL wrote the manuscript. All co-authors contributed substantially to revised drafts of the manuscript. We also thank two anonymous reviewers for their help in largely improving the manuscript.

Competing interests: We declare that we have no competing interests.

This article is protected by copyright. All rights reserved 
Data and materials availability: Raw sequencing RNA-Seq data for small giant clams featured herein have been made publicly available on the NCBI database (PRJNA579426), and all scripts discussed in the article can be found on Github (https://github.com/jleluyer/acclimabest). Raw meta-barcoding data are available here: (pending creation). Data for cultured Symbiodiniaceae have been previously deposited on the NCBI database: Levin et al. (2016)-BioProject NCBI: PRJNA295075, Gierz et al. (2017)BioProject NCBI: PRJNA342240. Data for Symbiodiniaceae from the reef coral $P$. damicornis (Mayfield et al., 2014) can be found on the NCBI database (Sequence Read Archive: SRR1030692 and BioProject: PRJNA227785), as well as on this modular, interactive website: http://symbiont.iis.sinica.edu.tw/coral_pdltte/static/html/index.html\#home.

This article is protected by copyright. All rights reserved 